\title{
CARACTERÍSTICAS DA VARIEDADE FREMONT QUANDO COMPARADAS COM AS DAS TANGERINAS 'PONKAN' E 'CLEMENTINA NULES'
}

\author{
ROSE MARY PIO², FERNANDO ALVES DE AZEVEDO³, JOSÉ DAGOBERTO DE NEGRI ${ }^{4}$, JOSÉ ORLANDO DE \\ FIGUEIREDO ${ }^{5}$, JAIRO LOPES DE CASTRO ${ }^{6}$
}

\begin{abstract}
RESUMO - O quadro varietal das tangerinas plantadas comercialmente é bastante restrito, concentrando-se na tangerina 'Ponkan' e no tangor 'Murcott'. Aumentar o número de variedades, assim como ampliar o período de safra são fatores importantes tendo em vista que trarão vantagens ao consumidor e ao produtor desse grupo de citros. No período de 2002 a 2005, foram estudadas as características da variedade Fremont e comparadas com as tangerinas ‘Ponkan' e ‘Clementina Nules', no município de Capão Bonito-SP. Pode-se concluir, dos resultados obtidos, que as plantas da tangerina Fremont são de porte reduzido (semi-anãs); os frutos apresentam características excepcionais para consumo in natura, maturação de meia-estação e período de colheita, que se estende por até três meses, sendo dessa maneira boa opção para plantios visando à entressafra da 'Ponkan'.
\end{abstract}

Termos para indexação: fruta fresca, qualidade, seleção, mercado, híbrido.

\section{CHARACTERISTICS OF FREMONT VARIETY COMPARED TO PONKAN AND CLEMENTINA NULES TANGERINES}

\begin{abstract}
Commercial grown tangerines variety are mainly restricted to a few options such as Ponkan tangerine and Murcott tangor. The increasing number of varieties as well as the harvest extending season is important, potentially benefiting consumers and producers of this kind of citrus. Fremont characteristics were compared to Ponkan and Clementina Nules tangerines at Capão Bonito County in São Paulo State from 2002 to 2005 . By the results, it was possible to conclude that Fremont trees were semi-dwarfed, the fruits had excellent characteristics for in natura consumption and a harvesting season enlargement of three months, therefore appearing to be a good alternative for orchards, aiming at Ponkan' off-season period.
\end{abstract}

Index terms: fresh fruit, quality, selection, market, varieties, hybrids.

\section{INTRODUÇÃO}

As tangerinas representavam, em 2002, cerca de $4 \%$ dos plantios de cítricos do Estado de São Paulo com uma área plantada de 25 mil hectares, perfazendo 604 mil toneladas de frutos produzidos, para um total da produção brasileira de 1,3 milhão (FNP, 2004). Devido à pequena variabilidade do grupo de tangerinas comerciais, os produtores têm poucas alternativas. Isso torna a cultura extremamente vulnerável, sendo necessária a ampliação da oferta de outras variedades. Quando se consideram as variedades comerciais, que produzem frutos de maturação precoce à meia-estação, tem-se como opção a tangerina 'Ponkan', representando 60\% dos plantios dentro do grupo, a mexerica-do-Rio, com 15\% (Pompeu Júnior, 2001) e a tangerina 'Cravo' em menor escala. Entretanto, alternativas vêm sendo propostas para esse período do ano.

Dentre quarenta e duas novas variedades que estão sendo estudadas pelo Centro Avançado de Pesquisa Tecnológica do Agronegócio de Citros Sylvio Moreira/IAC, em diferentes condições edafoclimáticas de São Paulo, a tangerina Fremont vem se mostrando bastante promissora, com excelente qualidade de fruto.

A Fremont é resultante do cruzamento entre as tangerinas Clementina e 'Ponkan', sendo estudada, primeiramente, por P.C. Reece, na Flórida, e posteriormente selecionada por J.R. Furr, na Califórnia, antes de ser liberada nos Estados Unidos, em 1964. Apresenta maturação precoce de seus frutos e é, indiscutivelmente, uma das mais atraentes tangerinas. Possui coloração de casca amareloavermelhada já no início da maturação, e forma de fruto e textura de casca muito semelhantes às clementinas (Saunt, 1990). Cabe mencionar que essa variedade, segundo Feichetenberger et al. (2005), possui a característica de apresentar tolerância à mancha-marrom de Alternaria
(Alternaria alternata), doença que afeta a tangerina 'Ponkan' e, principalmente, o tangor 'Murcott', aumentando demasiadamente os custos de produção da cultura.

A tangerina Clementina tem grande importância na região mediterrânea, em especial no Morrocos e na Espanha, onde se planta, basicamente a autêntica clementina sem sementes, e, devido a intensas observações, têm sido detectadas mutações de grande interesse. Esse fato veio possibilitar a obtenção de safras de clementinas, além dos meses tradicionais (novembro e dezembro), ou seja, de meados de outubro a meados de fevereiro (Saunt, 1990). Das muitas variedades que são cultivadas, podem ser destacadas algumas: Fina, Nules, Esbal, Oroval, Marisol, entre outras.

Existem muitas controvérsias sobre a origem da Clementina. Uma das teorias é que ela tenha surgido de um cruzamento acidental entre a mexerica comum do Mediterrâneo e a laranja-azeda conhecida como Granito. Outra hipótese é que ela apresenta características idênticas à variedade conhecida como tangerina Canton plantada nas províncias de Gwangxi e Guangdong, na China (Saunt, 1990).

Já a tangerina 'Ponkan' é originária da Ásia (Hodgson, 1967), e este grupo constitui-se num dos mais cultivados no mundo, sendo comum na China, Japão, Filipinas e Índia. É também o mais popular no Brasil (Saunt, 1990), representando, em 2001, 60\% dos plantios dentro do grupo das tangerinas (Pompeu Junior, 2001). São árvores de porte médio, com crescimento ereto, produtiva, mas com tendência a apresentar alternância de produção. Frutos grandes, de maturação meia-estação, com casca solta e sabor bastante doce, o que os torna muito apreciados para consumo in natura.

Esta pesquisa objetivou estudar as características da variedade Fremont em comparação com as tangerinas 'Ponkan' e 'Clementina Nules', em dois porta-enxertos.

\footnotetext{
${ }^{1}$ (Trabalho 171-2005). Recebido: 13-10-2005. Aceito para publicação: 30-05-2006. Apoio financeiro FAPESP.

2 Bióloga, Doutora, Pesquisadora Científica, Centro APTA Citros Sylvio Moreira/IAC, Cx.P. 04-CEP13.490970, Cordeirópolis-SP, Email:rose@centrodecitricultura.br. Autor para correspondência. Bolsista CNPq

${ }^{3}$ Eng.Agr., Doutor, Pesquisador Científico, Centro APTA Citros Sylvio Moreira/IAC.

${ }^{4}$ Eng.Agr., Centro APTA Citros Sylvio Moreira/IAC.

${ }_{5}^{5}$ Eng.Agr., Doutor, Pesquisador Científico, Centro APTA Citros Sylvio Moreira/IAC. Bolsista CNPq.

${ }^{6}$ Eng.Agr., Mestre, Pesquisador Científico, APTA Reg. Sudoeste Paulista.
} 


\section{MATERIAL E MÉTODOS}

Foram estudadas as características da tangerina Fremont (Citrus clementina hort. ex Tanaka x Citrus reticulata Blanco), tangerina 'Clementina Nules' (Citrus clementina hort. ex Tanaka) e tangerina 'Ponkan' (Citrus reticulata Blanco), em dois porta-enxertos: limão ‘Cravo' (Citrus limonia Osbeck) e tangerina ‘Cleópatra' (Citrus reshini hort. ex Tanaka).

\section{Instalação do experimento}

O experimento foi instalado, em 1996, no Pólo Regional de Pesquisa e Desenvolvimento do Sudoeste de São Paulo, localizado no município de Capão Bonito-SP, e conduzido com tratos rotineiros para a cultura, sem irrigação.

A experimentação foi implantada em um solo do tipo Latossolo Vermelho-Escuro-distrófico, textura argilosa, sendo que a altitude da Unidade é de $702 \mathrm{~m}$ e o clima do tipo Cfb, segundo a classificação de Köppen. A média anual de precipitação pluviométrica é de $1.216 \mathrm{~mm}$. A temperatura média anual é de $20,1^{\circ} \mathrm{C}$, sendo a média das máximas igual a $25,9^{\circ} \mathrm{C}$ e a média das mínimas igual a $14,3^{\circ} \mathrm{C}$ (Instituto Agronômico, 2002).

Os estudos foram realizados em quatro anos consecutivos (2002 a 2005), e o delineamento experimental usado foi o de blocos ao acaso, com oito repetições, em esquema fatorial $3 \times 2$ (três variedadescopa e dois porta-enxertos), com um total de seis tratamentos. Cada repetição foi composta de uma planta por parcela. Para obtenção de dados de produtividade, avaliaram-se seis blocos, enquanto, para as análises físico-químicas, os frutos foram coletados nas plantas dos demais blocos (dois), onde cada amostra possuía cinco frutos por planta.

\section{Avaliações}

Desenvolvimento vegetativo e produtividade das plantas

Avaliou-se o desenvolvimento vegetativo das plantas por meio de aferições da altura e diâmetro da copa. As mensurações foram realizadas com régua de madeira graduada, efetuando-se medições paralelas ao eixo de crescimento geopositivo da copa (altura) e paralelas ao solo, na altura de 1,5m (diâmetro), no ano de 2005. A colheita das tangerineiras foi monitorada durante o período de 2002 a 2004, e as produções foram obtidas com a pesagem direta de todos os frutos da planta.

Fez-se também uma projeção teórica para determinar o melhor espaçamento e uma estimativa de produtividade por área, para a variedade Fremont, baseando-se na fórmula desenvolvida por De Negri e Blasco (1991), onde se tem:

- distância entre linhas = diâmetro da copa + 2,5m;

- distância entre plantas = diâmetro da copa x 0,75.

\section{Análises físico-químicas}

As amostras foram coletadas no período de maio a agosto de cada ano, e as análises foram feitas no Laboratório de Qualidade e Pós-Colheita de Citros do Centro Avançado de Pesquisa Tecnológica do Agronegócio de Citros Sylvio Moreira/IAC, em Cordeirópolis-SP. A massa total dos frutos das amostras foi obtida em uma balança Filizola, com capacidade para $15 \mathrm{~kg}$ e sensibilidade de $5 \mathrm{~g}$, enquanto o rendimento de suco foi determinado após processamento em extratora OIC (Organização Internacional Centenário) modelo OTTO 1800 (filtro com diâmetro interno de $26,11 \mathrm{~mm}$, comprimento de $265 \mathrm{~mm}$, furos de diâmetro de $0,6 \mathrm{~mm}$ e área de vazão de $20 \%$ ), sendo calculado por meio da relação massa do suco/massa do fruto e expresso em porcentagem. O teor de sólidos solúveis totais $\left({ }^{\circ} \mathrm{Brix}\right.$ ou SST) foi determinado por leitura direta no refratômetro B\&S, modelo RFM 330. Os dados foram corrigidos pela temperatura e pela acidez do suco. A acidez total (AT) foi obtida por titulação de $25 \mathrm{~mL}$ de suco, com uma solução de hidróxido de sódio a 0,3125 de normalidade e usando-se a fenoftaleína como indicadora (Reed et al., 1986). Foi calculada a relação sólidos solúveis:acidez (ratio ou SST:AT).

\section{RESULTADOS E DISCUSSÃO}

\section{Desenvolvimento vegetativo e produtividade das plantas}

Comparando o desenvolvimento das plantas adultas por meio das aferições de altura e diâmetro médio das copas, no ano de 2005 (Tabela 1), verifica-se que as plantas de tangerina 'Ponkan' foram as que mais se desenvolveram em altura $(4,50 \mathrm{~m})$. Resultado similar foi obtido por Cunha e Salibe (1989), que compararam essa variedade com as tangerinas 'Dancy' e 'Cravo' e o tangor 'Murcott'. Para o parâmetro diâmetro de copa, observou-se a mesma tendência, porém a 'Clementina Nules' não diferiu estatisticamente da 'Ponkan' e não houve diferença entre os porta-enxertos.

Dentre as copas avaliadas, a tangerina Fremont apresentouse menos vigorosa, portanto de porte reduzido (Figura 1), e não diferiu da 'Clementina Nules', em ambas as aferições. Os dados encontrados neste trabalho estão de acordo com descrições dessa variedade

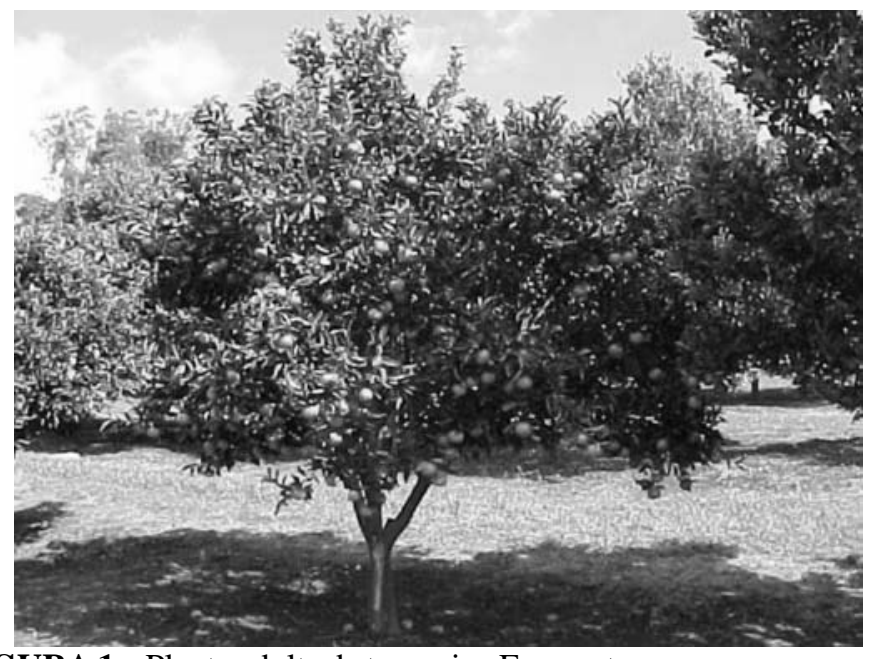

FIGURA 1 - Planta adulta de tangerina Fremont

TABELA 1 - Avaliações do desenvolvimento vegetativo de tangerineiras - altura e diâmetro de copa (Capão Bonito-SP, 2005)

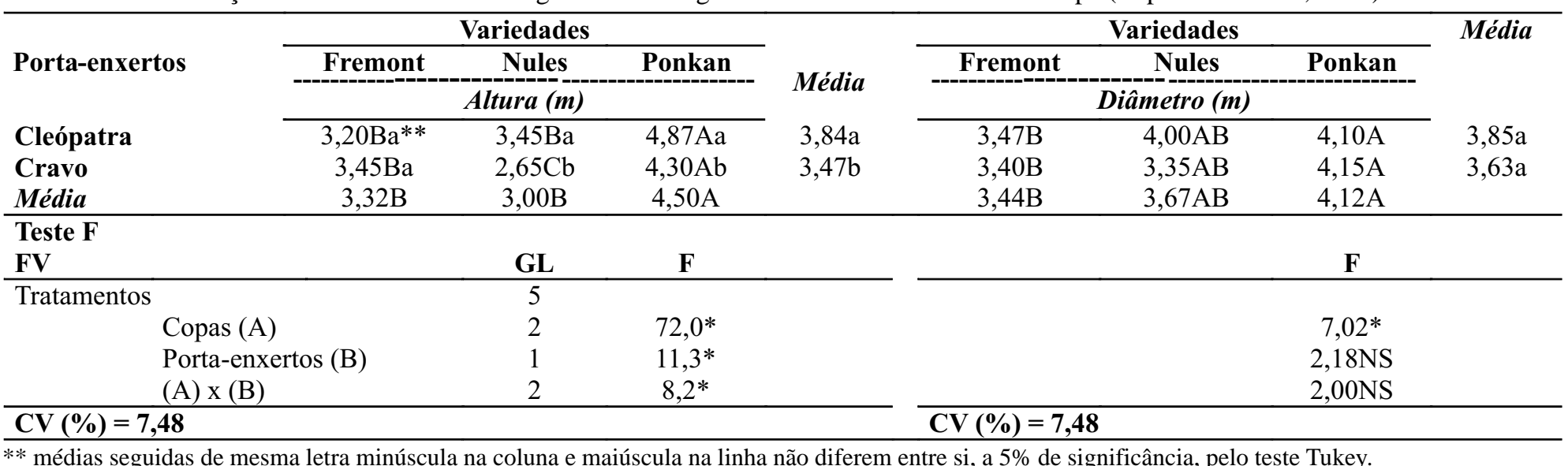


TABELA 2 - Produção média de frutos, em kg/planta de tangerineiras Fremont, Ponkan e Nules, no período de 2002 a 2004 (Capão Bonito-SP)

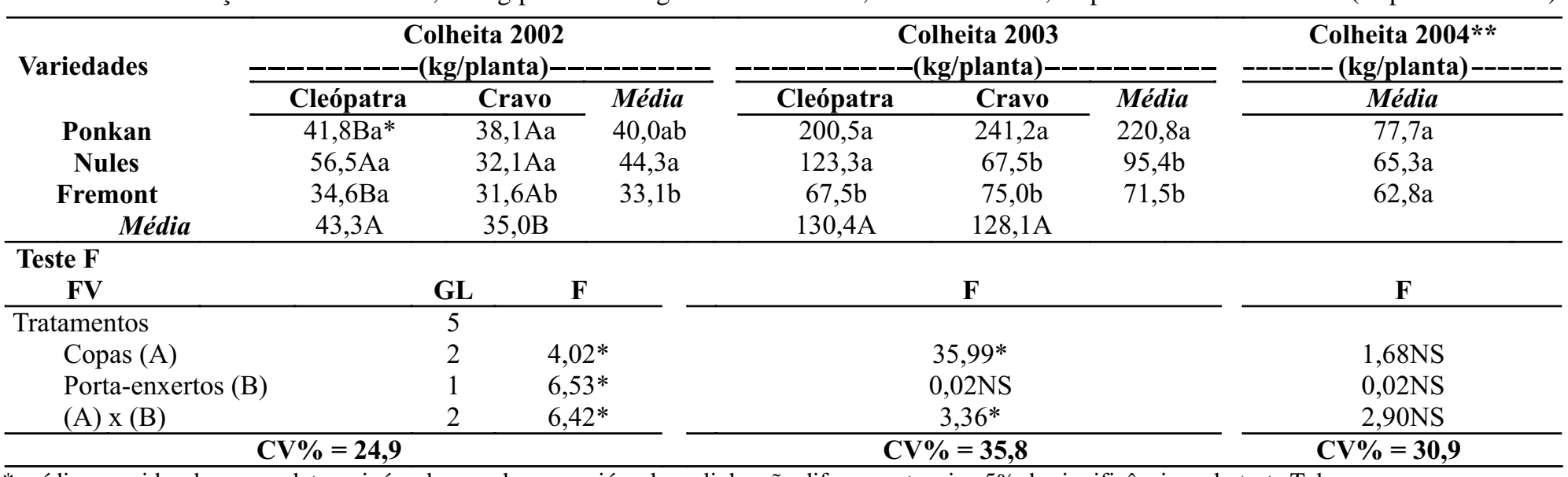

* médias seguidas de mesma letra minúscula na coluna e maiúscula na linha não diferem entre si, a 5\% de significância, pelo teste Tukey.

** não houve interação entre os fatores avaliados (copa x porta-enxerto)

realizadas por Hodgson (1967). Segundo classificação de Bitters et al. (1979), as tangerinas Fremont e 'Nules' seriam consideradas plantas semi-anãs em relação a padrões prestabelecidos (laranja doce, limão Rugoso e citrange Troyer). Nelas se observa redução de até $50 \%$ da copa em relação a esses padrões. Já a tangerina 'Ponkan' seria classificada como subestândarde (redução de apenas $25 \%$ da copa em relação aos padrões).

Quanto aos porta-enxertos utilizados, a tangerina 'Cleópatra' proporcionou maior altura às plantas em relação ao limão 'Cravo'. Esses resultados são similares em outras variedades-copa, como, por exemplo, o tangor 'Murcott', onde foram constatados aumentos no vigor e, conseqüentemente, maior desenvolvimento vegetativo das plantas sobre este porta-enxerto em comparação com o limão 'Cravo'; esses dados foram observados em Lavras-MG (Amaral et al., 1995) e Itirapina-SP (Figueiredo, 1997).

Quando se observam os dados das colheitas, nota-se, de maneira geral, que a tangerina 'Ponkan' apresentou maior produção, independentemente do porta-enxerto utilizado (exceto no ano de 2002) e a tangerina Fremont a menor, estando bastante correlacionado aos resultados de desenvolvimento vegetativo das plantas (Tabela 2).

O porta-enxerto 'Cleópatra' proporcionou maior produção às copas em relação ao limão 'Cravo', sendo que apenas no ano de 2002 se observaram diferenças significativas. Esses resultados, no geral, concordam com os de estudos similares, como, por exemplo, o tangor 'Murcott', onde aumentos de produção foram observados em Lavras-MG (Amaral et al., 1995) e Itirapina-SP (Figueiredo et al., 1997).

A arquitetura das plantas das tangerinas Fremont e 'Nules' traz uma série de vantagens sobre as plantas vigorosas. Uma planta pequena é uma unidade produtiva mais eficiente; o controle de pragas e doenças é mais eficaz e econômico; a colheita é facilitada e conseqüentemente mais barata (Duncan et al., 1978); e permite que o citricultor adense o plantio, aumentando consideravelmente o número de plantas por hectare. Esse adensamento é desejável e necessário para se incrementar a produção por unidade de superfície disponível e consequientemente a rentabilidade (Stuchi, 1994). Alguns problemas com a alta densidade de plantas por área seriam: alto custo inicial com aquisição de mudas e necessidade de podas anuais (Philipps, 1978).
Fazendo-se uma projeção teórica para determinar o espaçamento ideal de plantio para a tangerina Fremont, que foi a variedade de menor porte, baseado na fórmula descrita por De Negri e Blasco (1991), determinaram-se os seguintes valores: 5,97 m entre linhas (ruas) x 2,6 m entre plantas (645 plantas/ha) quando enxertadas em Cleópatra e 5,90 x 2,55m (667 plantas/ha) em Cravo. Nessa densidade de plantio, produtividades teóricas de aproximadamente 50ton/ha desta tangerina seriam obtidas em Capão Bonito-SP, o que é considerada uma boa produção para os citros em geral.

\section{Análises físico-químicas}

Nas tabelas 3 e 4, encontram-se os dados médios das características físico-químicas (massa dos frutos, rendimento, sólidos solúveis totais e acidez total do suco) das variedades Fremont, 'Ponkan' e 'Clementina Nules' nos porta-enxertos de tangerina 'Cleópatra' e limão 'Cravo'. Observa-se que, quanto à massa dos frutos, os valores apresentados para a variedade Fremont são menores, em média, quando comparados aos de 'Nules' e 'Ponkan'. Em ambos os porta-enxertos, os valores para Fremont são menores do que os citados por Figueiredo (1991) para a tangerina 'Ponkan', que é de 138g. Para a tangerina 'Clementina Nules', os valores observados foram maiores que os descritos na literatura (Castañer, 1995), demonstrando que esses frutos estão em estádio avançado de maturação ("bufados"). Também se observa que, a partir de junho, não ocorreram mais coletas de frutos da tangerina 'Clementina Nules' quando enxertada em limão 'Cravo'. Esse fato demonstra que essa variedade é bastante precoce, necessitando ser colhida entre os meses de março/abril, quer seja em porta-enxerto de Cravo, quer seja em Cleópatra.

Quanto ao rendimento de suco, nota-se que os valores para Fremont pouco se alteram no decorrer do período avaliado. Nas demais variedades, há grandes perdas de rendimento a cada coleta, chegando próximo de 40\%, como é o caso de 'Ponkan'/ 'Cravo'.

Analisando os valores de SST, AT e a relação SST/AT (Figura 2 e Tabela 4), observa-se que, na 'Ponkan', os valores de SST têm aumentos progressivos no decorrer das análises e queda dos valores de AT; como conseqüência, os valores da relação SST/

TABELA 3 - Massa do fruto e rendimento do suco de tangerinas Fremont, 'Ponkan' e 'Nules', no ano de 2004 (Capão Bonito-SP).

\begin{tabular}{|c|c|c|c|c|c|c|c|}
\hline \multirow{4}{*}{$\begin{array}{l}\text { Variedades } \\
\text { Fremont }\end{array}$} & \multirow[b]{2}{*}{ Porta-enxertos } & \multicolumn{3}{|c|}{ Massa fruto (g) } & \multicolumn{3}{|c|}{ Rendimento suco (\%) } \\
\hline & & $28 /$ maio & 21/jun. & 19/ago. & $28 /$ maio & 21/jun. & 19/ago. \\
\hline & Cleópatra & 126 & 131,5 & 119,5 & 44,6 & 41,3 & 36,5 \\
\hline & Cravo & 138 & 112 & 118 & 34,8 & 38,05 & 36,05 \\
\hline Nules & Cleópatra & 218 & 235,5 & 157,5 & 51,4 & 39,25 & 42,7 \\
\hline & Cravo & 121 & $*$ & $*$ & 45,5 & $*$ & $*$ \\
\hline Ponkan & Cleópatra & 190 & 196,5 & 163 & 44,25 & 39,3 & 40 \\
\hline & Cravo & 206 & 222,5 & 228 & 46,1 & 34,45 & 29,15 \\
\hline
\end{tabular}


TABELA 4 - Valores de sólidos solúveis totais (SST) e acidez total (AT) de frutos de tangerinas Fremont, 'Ponkan’ e 'Nules', em 2004 (Capão Bonito-SP).

\begin{tabular}{|c|c|c|c|c|c|c|c|}
\hline \multirow[b]{2}{*}{ Variedades } & \multirow[b]{2}{*}{ Porta-enxertos } & \multicolumn{3}{|c|}{ SST ( ${ }^{\circ}$ Brix) } & \multicolumn{3}{|c|}{ AT (\%) } \\
\hline & & $28 /$ maio & 21/jun. & 19/ago. & $28 /$ maio & 21/jun. & 19/ago. \\
\hline \multirow[t]{2}{*}{ Fremont } & Cleópatra & 9,35 & 9,75 & 10,80 & 0,50 & 0,47 & 0,41 \\
\hline & Cravo & 9,50 & 9,30 & 10,25 & 0,47 & 0,51 & 0,40 \\
\hline \multirow[t]{2}{*}{ Nules } & Cleópatra & 9,10 & 9,10 & 10,70 & 0,77 & 0,45 & 0,63 \\
\hline & Cravo & 9,80 & $*$ & $*$ & 0,69 & $*$ & $*$ \\
\hline \multirow[t]{2}{*}{ Ponkan } & Cleópatra & 8,75 & 9,65 & 11,80 & 0,52 & 0,36 & 0,27 \\
\hline & Cravo & 8,80 & 9,25 & 11,85 & 0,38 & 0,36 & 0,32 \\
\hline
\end{tabular}

* sem frutos para coleta

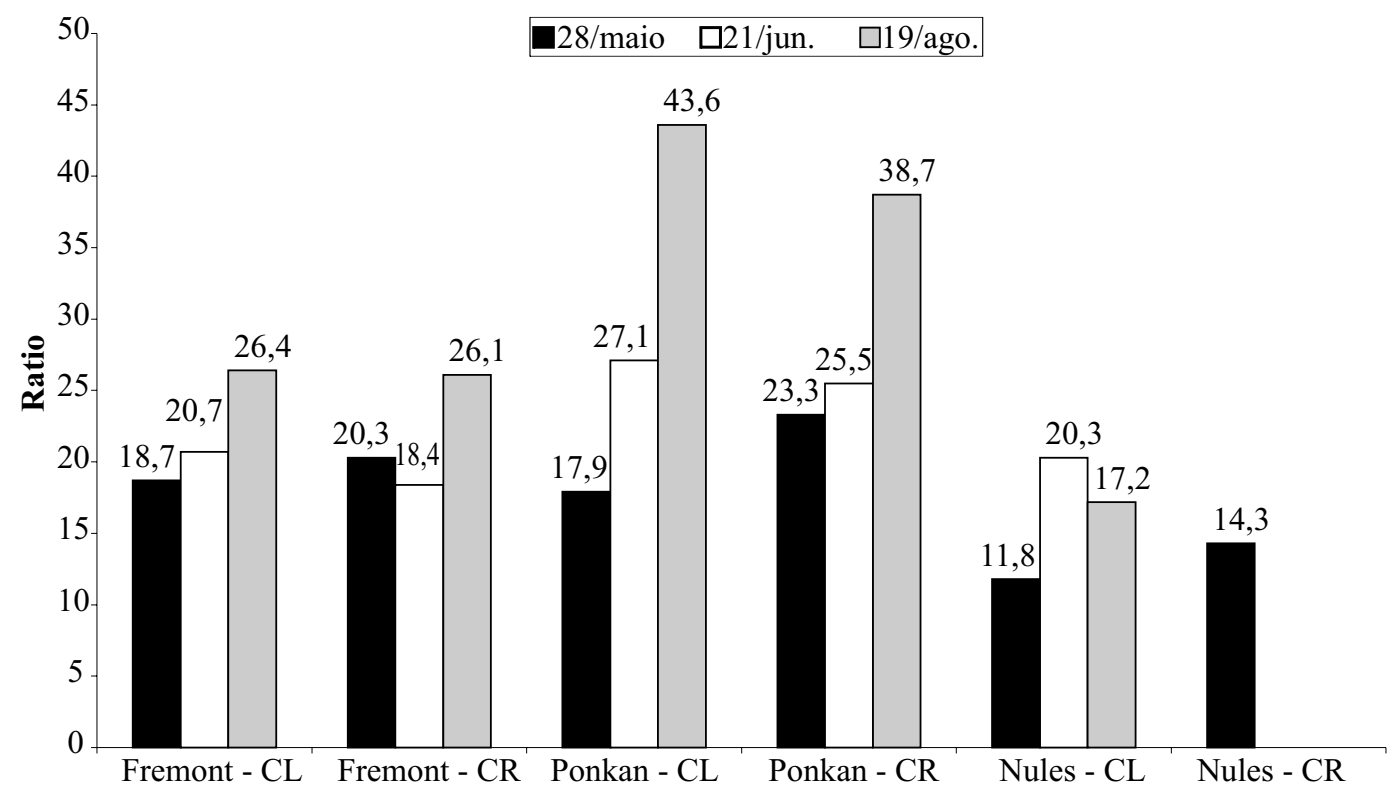

FIGURA 2 - Valores da relação sólidos solúveis totais/acidez total do suco (ratio) dos frutos de tangerinas Fremont, 'Ponkan' e 'Nules' sobre dois porta-enxertos, em três períodos distintos, do ano de 2004, em Capão Bonito-SP (CL - tangerina 'Cleópatra'; CR - limão 'Cravo').

AT são maiores a cada análise, chegando a 43,5, em meados de agosto, o que a torna inviável para consumo. Vale destacar que, para a variedade Fremont, esses valores não são tão variáveis durante o período analisado, demostrando que essa variedade pode ser armazenada, ainda na planta, por um período mais extenso que a 'Ponkan' e 'Nules', sendo, assim, boa opção para a ampliação da safra do grupo das tangerinas.

Quando comparadas com a 'Ponkan', as variedades Fremont e 'Clementina Nules' apresentam maior firmeza de casca. A última variedade deve ser colhida quando ainda a casca não se separou dos gomos, estando, dessa maneira, adequados para consumo. Merece destaque que, nos frutos da variedade Fremont, essa característica, assim como as organolépticas permaneceram

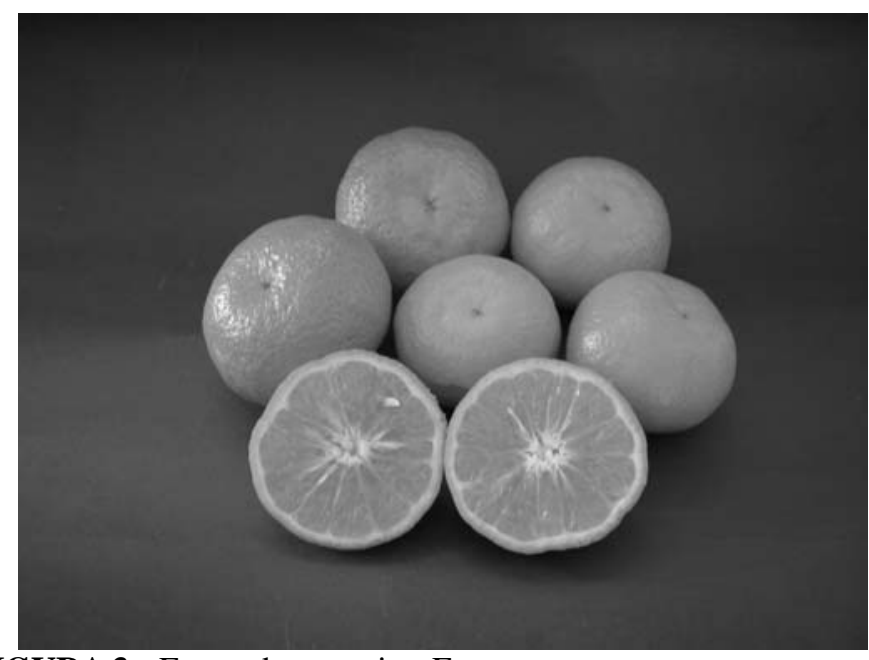

FIGURA 3 - Frutos de tangerina Fremont adequadas por três meses ainda na planta, sem perder a qualidade da fruta (Figura 3).

\section{CONCLUSÕES} (semi-anãs).

1. As plantas da tangerina Fremont são de porte reduzido

2. Os frutos apresentam características excepcionais para consumo in natura.

3. A tangerina Fremont é uma boa opção para plantios visando à entressafra da 'Ponkan', por produzir frutos de maturação tardia.

\section{REFERÊNCIAS}

AGRIANUAL 2005: anuário estatístico da agricultura brasileira. São Paulo: FNP Consultoria \& Comércio., 2004. p.287-320

AMARAL, A. M.; PENIDO, R.T.M.; SOUZA, M. Avaliação do vigor da tangoreira 'Murcott' sobre dois porta-enxerto. Revista Brasileira de Fruticultura, Jaboticabal, v.17, n.2, p.131-136, 1995.

BITTERS, W.P.; COLE, D.A.; McCARTY, C.D. Facts about dwarf citrus trees. Citrograph, Fresno, v.64, n.3, p.54-56, 1979.

CASTAÑER, M.A. Produccion de agrios. Madrid: Ediciones MundiPrensa, 1995. 286p.

CUNHA, R.J.P.; SALIBE, A.A. Comportamento de tangerineiras 'Cravo, 'Dancy' e "Ponkan" (Citrus reticulata Blanco) e do tangor 'Murcote' (Citrus sinensis (L.) Osbeck x Citrus reticulata Blanco) em porta-enxertos de limoeiro 'Cravo'(Citrus limonia Osbeck). In: CONGRESSO BRASILEIRO DE FRUTICULTURA, 10., Fortaleza,1989. Anais... Fortaleza: Sociedade Brasileira de Fruticultura, 1989. v.1, p.77-85 
DE NEGRI, J.D.; BLASCO, E.E.A. Planejamento e implantação de um pomar cítrico. In: RODRIGUEZ, O. et al. (Ed.). Citricultura brasileira. 2.ed. Campinas: Fundação Cargill, 1991. v.1, p.318332.

DUNCAN, J.H.; SPROULE, R.S.; BEVINGTON, K.B. Commercial application of vírus induced dwarfing. Proceedings of the International Society of Citriculture, Riverside, p.317-319, 1978.

FEICHETENBERGER, E.; SPÓSITO, M.B.; PIO, R.M.; CASTRO, J.L. Seleção de híbridos de tangerinas e híbridos de citros para tolerância à mancha-marrom de alternaria (Alternaria alternata Keissler). Citricultura Atual, Cordeirópolis, v.8, n.45, p.8-10, 2005.

FIGUEIREDO, J.O. de Variedades-copa de valor comercial. In: RODRIGUEZ, O.; VIEGAS, F.; POMPEU JÚNIOR, J.; AMARO, A.A. (Ed.). Citricultura Brasileira. Campinas: Fundação Cargill, 1991. v.1, p.228-264.

FIGUEIREDO, J.O.de; POMPEU JÚNIOR, J.; PIO, R.M.; TEÓFILO SOBRINHO, J.; DOMINGUES, E.T.; BLASCO, E.E. A. Produções iniciais de tangor 'Murcott' sobre 16 porta-enxertos, na região de Itirapina-SP. Revista Brasileira de Fruticultura, Jaboticabal, v.19, n.2, p.191-197, 1997.
HODGSON, R.W. Horticultural varieties of Citrus. In: REUTHER, W. Et al. (Ed.). The Citrus industry. Riverside: University California, 1967. v.1, p.461-591.

INSTITUTO AGRONÔMICO. Normais climatológicas de 1961 a 1990. Campinas: Centro de ecofisiologia e biofísica. Setor de climatologia, 2002.

PHILLIPS, R.L. Citrus tree spacing and size control. Proceedings of the International Society of Citriculture, Riverside, p.319-324, 1978.

POMPEU JÚNIOR, J. Rootstocks and scions in the citriculture of de São Paulo State. In: INTERNATIONAL CONGRESS OF CITRUS NURSERYMEN, 6., 2001, Ribeirão Preto. 2001. Proceedings... Ribeirão Preto: EECB/Fundecitrus, 2001. p. 75-82.

REED, J.B.; HENDRIX JR, C.M.; HENDRIX, D.L. Quality control manual for citrus processing plants. Safety Harbour: Intercit, 1986. v.1, 250p.

SAUNT, J. Citrus varieties of the world. Norwich: Sinclair International, 1990. p.60-62.

STUCHI, E.S. Controle do tamanho de plantas cítricas. Laranja, Cordeirópolis, v,15, n.2, p.295-342, 1994. 